\title{
Current management of distal radius fractures and their complications
}

\author{
Stefan Quadlbauer ${ }^{1}\left[\right.$ [ Martin Leixnering ${ }^{1}$
}

Received: 3 February 2020 / Published online: 19 March 2020

c) Springer-Verlag GmbH Germany, part of Springer Nature 2020

"The wrist is the key joint of the hand" (Bunnell) [1] and represents together with the forearm an inseparable anatomi$\mathrm{cal}$ and biomechanical unit. The wrist as an executive part of the body, enables optimal positioning of "the hand" to allow the grasping function. Consequently, the distal radius and ulna form the distal radioulnar as well as the radiocarpal joint and both are important to carry out daily activities.

Injuries to the distal radius are one of the most common in the upper extremities and forecasts predict a significant increase in the future. This perhaps accounts for the many new publications emerging to improve treatment and outcome.

Although, every orthopedic or hand surgeon is faced with this very commonly occurring type of injury, still no unanimous consensus in the literature has been found about the best form of treatment. Even basic questions for example, which fracture has to be treated operatively or conservatively and which operative fixation technique offers the best solution for the patient in respect of functional outcome and lowest complication rates are not clarified. This is particularly true in elderly patients. None of the routine treatments we use are evidence based. This subject is so controversial that even Cochrane data base reviews are unable to give definitive recommendations for optimal treatment. Furthermore, today's available classifications are more suitable for research purposes than supporting the treating surgeons in their decision-making process.

The present anthology "Current Management of Distal Radius Fractures and their Complications" attempts to summarize the current trends from the literature regarding fracture classification (with the additional use of CT Scans) [2], indications for conservative/operative treatment [3], surgical techniques [3], arthroscopic-assisted treatment/concomitant injuries [4], rehabilitation [5], complications [6], instability

Stefan Quadlbauer

stefan.quadlbauer@auva.at

1 AUVA Trauma Hospital Lorenz Böhler, 1200 Vienna, Austria of the distal radioulnar joint [7], corrective [8,9] and salvage procedures [10]. It has no claims to represent the entire spectrum, but rather attempts to assist the treating surgeons in their decisions to provide the optimal treatment for individual distal radius fractures.

Nine different expert hand surgeons were invited to share their experiences and know how when treating distal radius fractures. They also provided their critical assessment of the current emerging literature. These included their expertise and preferred treatment method. All authors work in central Europe, and are confronted daily with injuries to the hand. Therefore, compiling this manuscript inspite of their large clinical workload deserves our greatest respect and gratitude. Without their input and excellent performance, completion of this very high-quality anthology would not have been possible.

\section{References}

1. Tubiana R (1981) Architecture and functions of the hand. In: Tubiana R (ed) The Hand, vol 1. W.B Saunders Ltd, Philadelphia, p 19105

2. Hintringer W, Rosenauer R, Pezzei C et al (2020) Biomechanical considerations on a CT based treatment-oriented classification in radius fractures. Arch Orthop Trauma Surg. https://doi. org/10.1007/s00402-020-03405-7

3. Leixnering M, Rosenauer R, Pezzei $C$ et al (2020) Indications, surgical approach, reduction and stabilization techniques of distal radius fractures. Arch Orthop Trauma Surg. https://doi. org/10.1007/s00402-020-03365-y

4. Kastenberger T, Kaiser P, Schwendinger P et al (2020) Arthroscopic assisted treatment of distal radius fractures and concomitant injuries. Arch Orthop Trauma Surg. https://doi.org/10.1007/ s00402-020-03373-y

5. Quadlbauer S, Pezzei C, Jurkowitsch J et al (2020) Rehabilitation after distal radius fractures-is there a need for immobilization and physiotherapy? Arch Orthop Trauma Surg. https://doi. org/10.1007/s00402-020-03367-w

6. Rosenauer R, Pezzei C, Quadlbauer S et al (2020) Complications after operatively treated distal radius fractures. Arch Orthop Trauma Surg. https://doi.org/10.1007/s00402-020-03372-z 
7. Spies CKG, Langer M, Müller L et al (2020) Distal radioulnar joint instability - current concepts of treatment. Arch Orthop Trauma Surg. https://doi.org/10.1007/s00402-020-03371-0

8. Terzis A, Koehler S, Sebald J, Sauerbier M (2020) Ulnar shortening osteotomy as a treatment of symptomatic ulnar impaction syndrome after malunited distal radius fractures. Arch Orthop Trauma Surg. https://doi.org/10.1007/s00402-020-03374-x

9. Krimmer H, Schandl R, Wolters R (2020) Corrective osteotomy after malunited distal radius fractures. Arch Orthop Trauma Surg. https://doi.org/10.1007/s00402-020-03370-1
10. Keuchel T, Quadlbauer S, Jurkowitsch J et al (2020) Salvage procedure after malunited distal radius fractures and management of pain and stiffness. Arch Orthop Trauma Surg. https://doi. org/10.1007/s00402-020-03369-8

Publisher's Note Springer Nature remains neutral with regard to jurisdictional claims in published maps and institutional affiliations. 